\title{
Apis mellifera adansonii Is the Most Defensive Honeybee in Uganda
}

\author{
Patrice Kasangaki iD, ${ }^{1}$ Gideon N. Nyamasyo, ${ }^{2}$ Paul N. Ndegwa, \\ Christopher Angiro, ${ }^{1}$ and Robert Kajobe ${ }^{3}$ \\ ${ }^{1}$ National Livestock Resources Research Institute (NaLIRRI), P.O. Box 96, Tororo, Uganda
${ }^{2}$ School of Biological Sciences, University of Nairobi, P.O. Box 30197-00100, Nairobi, Kenya
${ }^{3}$ Rwabitaba Zonal Agricultural Research and Development Institute (RwabiZARDI), P.O. Box 96, Fort Portal, Uganda \\ Correspondence should be addressed to Patrice Kasangaki; pkasangaki@gmail.com
}

Received 29 November 2017; Accepted 16 May 2018; Published 21 June 2018

Academic Editor: G. Wilson Fernandes

Copyright (C) 2018 Kasangaki Patrice et al. This is an open access article distributed under the Creative Commons Attribution License, which permits unrestricted use, distribution, and reproduction in any medium, provided the original work is properly cited.

\begin{abstract}
Honeybee defensive behaviour is an important trait for selection of honeybees for breeding programs. We evaluated the variation in honeybee defensive behaviour with environmental factors and hive conditions. Factors such as the difference in the agro-ecological zones, colony strength, mean elevation, type of bee hive used, and the vegetation cover were considered. The number of honeybees attacking the researchers' protective gear within one minute of disturbance was recorded per colony and analyzed. Apis m. adansonii was found to be the most defensive. Variations in the agro-ecological zones, colony strength, and mean elevation were found to significantly influence the defensive behaviour of the honeybees. Honeybee colonies in the Mid North AEZ were the most defensive. The type of bee hive and vegetation cover did not have any influence on the defensive behaviour. From this study, we suggest that selection of honeybees that are less defensive for breeding programs should consider A. m. scutellata and honeybee colonies from West Nile and Southern Highland AEZs at higher elevations.
\end{abstract}

\section{Introduction}

In Africa, there are several races, subspecies, or ecotypes of honeybees (Apis mellifera L.) [1]. There is a high degree of inbreeding or hybridization among all the subspecies of A. mellifera $[2,3]$ resulting in different behavioural patterns and variation in response to attack or threat [4]. The most important behaviour of a honeybee colony is reproduction and colony defense $[5,6]$. Although the defensive behaviour of honeybees is advantageous for their evolutionary and ecological success, it is disadvantageous to human beings [7] who have always robbed the bees of their honey and other products. The defensive behaviour makes colony management difficult [8] and yet defending the honeybee colony and its resources is crucial in maintaining the colony integrity [9].

Honeybee colony defense is a social behaviour in which individual honeybees exhibit complicated pattern of actions and a variety of traits such as defensiveness (aggressiveness), gentleness, or docility $[6,9,10]$. It involves individual worker bee behaviour and a coordinated colony response with a group effect [8]. The defensive behavioural traits are particularly important in guarding, recruiting, alerting, attracting, biting, stinging, and pursuing enemies $[4,11]$. Such kind of behaviour is not yet well documented for the honeybees in the agro-ecological zones of Uganda.

Honeybee defensive behaviour is not only affected by environmental conditions but also by genetic constitution [12]. The defensive behaviour of African honeybees is related to environmental conditions and provocative situations [13, 14]. The defensive strategy employed by honeybees depend on the type of the potential attacker [15] and is induced and moderated by alarm pheromones [16] which are produced in the mandibular gland and sting apparatus of worker bees. Corner [17] reported that the defensive behaviour of Apis mellifera varies widely with geographical region and elevation throughout East Africa citing honeybees in western 
Uganda as being less defensive than those in the other parts of the country. Honeybee alarm pheromone is made of a compound called isoamyl acetate (IAA) which is a bananalike odour substance [18]. This substance is produced in the sting apparatus of worker bees. IAA elicits more stinging activity than any of the other defensive compounds acting as a target-marking pheromone and guiding other defenders to the sting site [16]. Together with visual cues such as rapid vibrations, quick movement around the colony, and olfactory cues, alarm pheromones elicit stinging by the honeybees [19].

In order to realize a profit from beekeeping, a beekeeper needs honeybee colonies which have a good temperament in terms of defensiveness. An understanding of the defensive behaviour of the honeybees in the agro-ecological zones of Uganda is very important in the development of the apiculture industry since many people are deterred from beekeeping by this behaviour of honeybees. The honeybee defensive behaviour can be an important trait for selecting honeybees for breeding [8]. This study therefore compared the defensive behaviour of two honeybee races (A. mellifera adansonii and A. m. scutellata) in the agro-ecological zones of Uganda. We tested the hypothesis that there is no difference in the defensive behaviour of the honeybees across the agroecological zones of Uganda.

\section{Materials and Methods}

2.1. Study Area. This study was carried out in nine agroecological zones (AEZs) of Uganda. The AEZs classification was based on the distinct vegetation type, elevation, climatic conditions, soils, and other physical factors, which are used to predict the potential productivity for various crops according to their specific environmental and management needs [20] as follows: Eastern, Lake Albert Crescent, Lake Victoria Crescent, Mid Northern, South East, Southern Dry lands, Southern Highlands, West Nile, and Western Highlands (Figure 1). The Karamoja Drylands was not sampled in this study given the nature of the beekeeping in the area (bee hives are placed high in the trees making observations difficult and dangerous). At least four apiaries were sampled per agroecological zone and a total of thirty-nine apiaries all together.

2.2. Sampling Techniques. Five honeybee colonies were assessed per apiary. In each apiary, the colonies were selected in such a way that the next colony to be observed was not influenced by the $1^{\text {st }}$ colony (test colonies were separated by either 2 or 3 other colonies). Distance between the test colonies was not measured for two reasons: (i) to reduce the time spent in the apiary and (ii) to limit disturbance before sampling. During the colony observations, the defensive behaviour of the colonies was recorded by observing the number of honeybees attacking/stinging the researcher's gloves and overall within one (01) minute of disturbance (hitting the hive lid with a hive tool three times and removing the top cover for KTB and Langstroth and opening one side of the hive in case of local or Johnson hives) [21,22]. Fresh gloves were worn before moving to the next colony and the overalls properly smoked to remove the smell of the alarm pheromone from them. Both the gloves and the overalls were

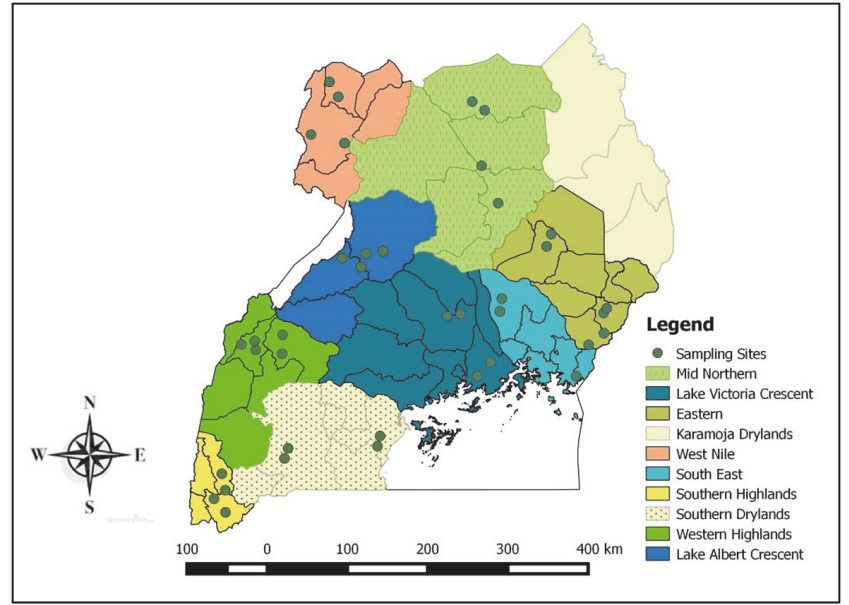

FIGURE 1: Location of the study sites in the agro-ecological zones of Uganda.

washed before use in the next apiary. The defensive behaviour was scored as $1=>10$ bee stings (very defensive), $2=6-9$ bee stings (moderate), and $3=0-5$ bee stings (gentle) [10, 23]. The vegetation cover around each apiary was observed and recorded as $1=$ thick; $2=$ moderate; $3=$ sparse. This was considered by looking at the herbs, shrubs, and trees around the apiary including both natural and plantations.

Four types of bee hives used by the beekeepers were compared (Langstroth, KTB, Local and Johnson). Colony strength was estimated by observing the number and proportion of combs covered by the adult bees, number and proportion of the combs covered by brood, and the amount of pollen and nectar collected. Averages of these observations were taken as $1=$ strong colony, $2=$ moderately strong colony, and 3 = weak colony. A GPS receiver was used to record the geographical coordinates and altitude of the sampling sites. Elevation gradients were categorized as Foot hill $(500-1000 \mathrm{~m})$, Montane $(1001-1500 \mathrm{~m})$, and Sub Alpine (1501-2000m) [24]. The honeybee races were determined through molecular techniques in another study [25].

2.3. Statistical Analysis. All statistical analyses were carried out using SPSS version 16.0. Mann-Whitney $U$ tests were used to compare the defensive behaviours of $A$. m. adansonii and A. m. scutellata. Generalized Linear Models (GLM) were used to evaluate factors associated with defensive behaviour of the honeybees and for significant results, Univariate Analysis of Variance Model (UAVM) was used to test for between-subject effects of significance from GLM. KruskalWallis Test was used to compare the defensive behaviour of the honeybee colonies in the AEZs. The same test was used to compare the defensive behaviour of the colonies with the colony strength and elevation gradient. In cases where significant differences were obtained, Mann-Whitney tests were conducted to compare pairs of categories. The mean defensive behaviours were used to compare the defensive behaviour of the honeybees in the AEZs, and with colony strength and elevation gradient. 
TABLE 1: Effects of environmental and colony factors on honeybee colony defensive behaviour.

\begin{tabular}{lcc}
\hline Source & df & P \\
\hline AEZ & 8 & 0.001 \\
Colony strength & 2 & $<0.001$ \\
Bee hive type & 3 & 0.241 \\
Vegetation cover & 2 & 0.246 \\
Elevation & 2 & 0.011 \\
\hline
\end{tabular}

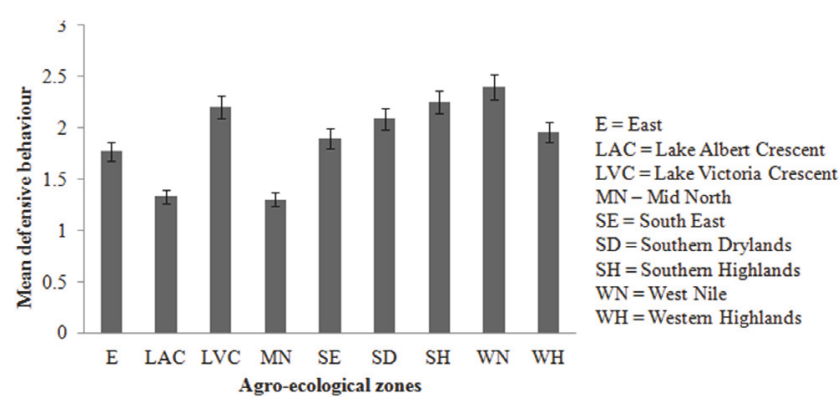

FIgURE 2: Comparison of the defensive behaviour of the honeybees in the AEZs of Uganda. The defensive behaviour was scored as $1=$ very defensive; 2 = moderate; and 3 = less defensive.

\section{Results}

3.1. Defensive Behaviour of A. m. adansonii and A. m. scutellata. There was a significant difference in the defensive behaviour between the two honeybee races $(\mathrm{U}=3.107, \mathrm{Z}=$ -2.207, $\mathrm{N}=175, \mathrm{P}=0.03$; Mann-Whitney $\mathrm{U}$ test) with $A . m$. adansonii being more defensive.

3.2. Factors Associated with Defensive Behaviour of the Honeybees. Colony strength, AEZs, and elevation had highly significant effects on the defensive behaviour of the honeybees ( $P$ $<0.01$ ) (Table 1). On the other hand, vegetation and bee hive type did not significantly influence the defensive behaviour $(\mathrm{P}>0.05)$.

The UAVM accuracy was significant $(\mathrm{P}<0.001)$ and it was able to account for over $90.4 \%$ of the variations $\left(R^{2}=0.920\right.$; adjuster $\left.\mathrm{R}^{2}=0.904\right)$. AEZs, colony strength, and elevation were all highly significant at $\mathrm{P}<0.001$. The interaction between all the three factors was significant $(\mathrm{df}=2 ; \mathrm{f}=1.431$; $\mathrm{P}=0.016$ ).

The defensive behaviour of the honeybees varied across the AEZs. Mid North AEZ had the most defensive honeybee colonies, while West Nile AEZ had the least defensive (Figure 2). Pairwise comparison of the defensive behaviour in the AEZs showed that Mid North AEZ was significantly different from the rest of the AEZs except Lake Albert Crescent AEZ. The rest of the AEZs were only significantly different from one to three of the other of the AEZs (Figure 2).

There was a significant positive correlation between honeybee defensive behaviour and colony strength implying that the stronger the colony, the more defensive the honeybees (Figure 3). For elevation, the most defensive honeybees were found at the foothill (500-1000 meters above sea level), while

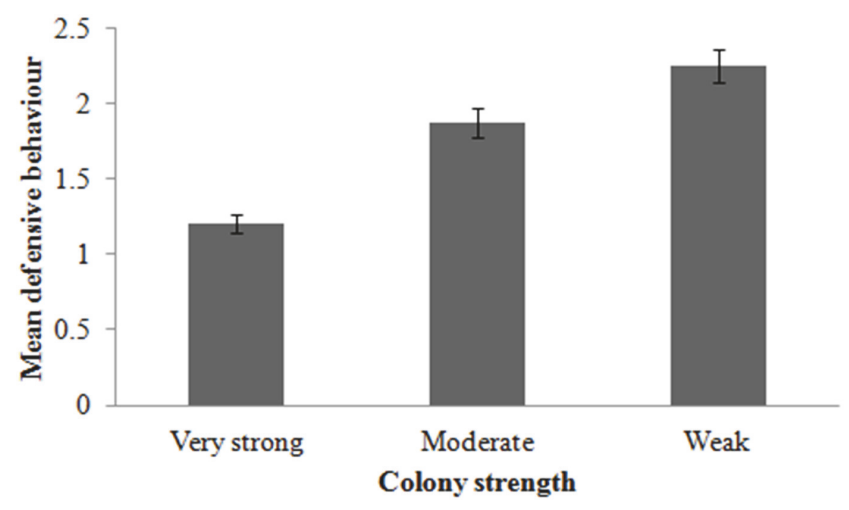

FIGURE 3: Comparison of the defensive behaviour of the honeybees with the colony strength in the AEZs of Uganda. The defensive behaviour was scored as $1=$ very defensive; 2 = moderate; and $3=$ less defensive.

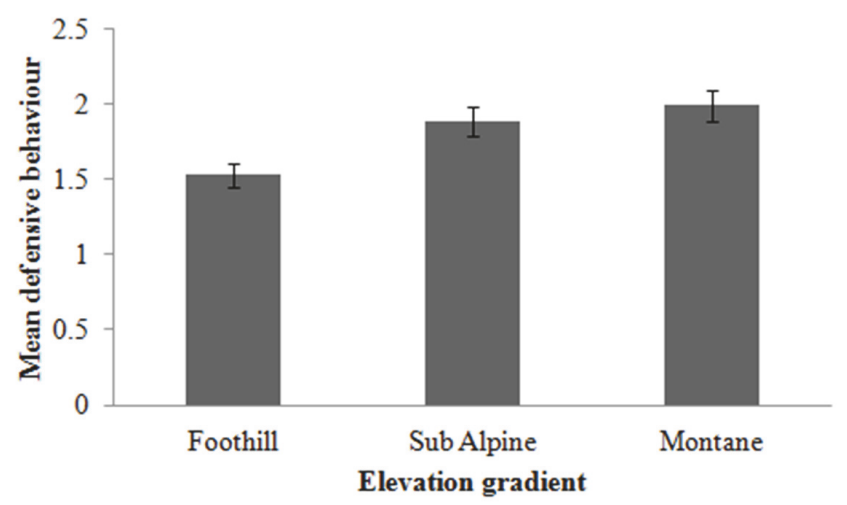

FIGURE 4: Comparison of the defensive behaviour of the honeybees according to elevation gradient. The defensive behaviour was scored as $1=$ very defensive; 2 = moderate; and $3=$ less defensive.

at the sub Alpine (1000-1500m) and Montane (1500-2000m) the honeybees were less defensive (Figure 4).

\section{Discussions}

Apis mellifera scutellata is less defensive compared to A. $\mathrm{m}$. adansonii in the agro-ecological zones of Uganda as confirmed by the significant difference in the defensive behaviour between $A$. $m$ scutellata and $A$. $m$. adansonii. This result is in agreement with that of Alemu et al. [14] who studied the defensive behaviour of A.m. scutellata in Ethiopia and found out that these bees are not very defensive. Mistroa et al. [26] described A. $m$. adansonii as the African honeybee which has an inconvenient aggressive behaviour which is only compensated by its large honey output when in tropical climate, while Hussein [27] described A. m. adansonii as small, very productive, and aggressive honeybees in Guinea-Bissau and the most defensive among wild colonies in Senegal. Honeybee colony defense is the behaviour individual bees exhibit in guarding against intruders and is correlated to response in alarm pheromone [19]. African honeybees are known for their defensive tendencies compared to European bees $[9,28]$ 
and are more productive. Among the African races of honeybees, A. $m$. scutellata is highly known for its defensiveness and has been highly studied [4, 9, 19, 29, 30]. Woyke [31] and Segeren [32] described both A. m. scutellata and A. m. adansonii as having pronounced defensive behaviour. Some studies on honeybee defensive behaviour have described $A$. $m$. scutellata as the most defensive honeybee $[9,33,34]$. However, most of these researches were in comparison to the European honeybees which are generally known to be gentle.

Several factors are known to influence honeybee defensive behaviour [14]. In this study, AEZs, colony strength, and elevation had significant effects on the defensive behaviour of the honeybees. On the other hand, type of bee hive and vegetation cover did not show any significant effects on the defensive behaviour of the bees. Geographical differences are known to influence honeybee defensive behaviour [17]. From the analyses in this study, it was found that there were significant differences in the defensive behaviour of the honeybees in the different AEZs. Specifically, the honeybees in the Mid North and Lake Albert Crescent agro-ecological zones were the most defensive, while those in the West Nile AEZ were the least defensive. Different AEZs have different local climatic conditions to which the honeybees are adapted $[23,35,36]$. Variations in these climatic and environmental factors could explain the differences in the defensive behaviour across the AEZs of Uganda. For instance, temperature influences bee activity and diffusion of semiochemicals, thus directly affecting the defensive behaviour of the bees.

Honeybee colony strength is associated with large number of brood and other resources and productivity depends on traits such as defensiveness [37]. Wray et al. [38] in a study on collective personalities of honeybee colonies attributed the difference in the defensive behaviour of honeybees to differences in population size, environment, or available resources. Resources in a honeybee colony include bee brood, pollen, and honey all of which need to be defended. The higher the amount of resources (colony strength) the higher the defensive behaviour of the honeybees as was observed in this study. Paleolog [39] noted that colony strength affects the stinging behaviour of honeybees. Adedeji et al. [40] associated the high defensive characteristics of the honeybees in the Rivers State, Nigeria, with large and strong colonies. Strong colonies always have good reserves of honey and pollen which is often detected by bees from other colonies that tend to remove (rob) them [32] which stimulate the defensive instincts in the strong colony. Nakamura et al. [41] observed that a honeybee colony with a large number of brood is very active and defensive and therefore not easy to harvest honey from it. This is in agreement with the results of this study which showed that the stronger the honeybee colony the higher its defensive behaviour as observed in the Mid North AEZ.

Effects of elevation on honeybee defensive behaviour have been studied $[42,43]$. Our study found out that the honeybees were more defensive at the foothill (low elevation) compared to the sub Alpine and montane (medium and higher elevations, respectively). This is in agreement with the study by Omer [44] who found out that honeybees are more defensive at lower elevations which are hotter compared to the higher elevations. This brings in the issue of temperature as one of the factors that influences honeybee defensive behaviour. Corner [17] described the defensive behaviour of tropical bees as varying widely with geographical region and elevation citing the honeybees of Uganda at higher elevations of western 'Province' as being less 'aggressive' than honeybees from other parts of the country. This observation is in agreement with our results which show that the Mid North and Lake Albert Crescent AEZs with the lowest mean elevations, respectively, had the most defensive honeybees, while Southern Highland AEZ with the highest mean elevation had less defensive bees. However, West Nile AEZ which is in the low elevation region also had less defensive honeybees. In the West Nile AEZ, modern beekeeping practices are adopted including apiary management and colony inspection in which the bees get frequent encounters with human beings and get adapted to such disturbances, thus accounting for the less defensive behaviour of the honeybees in this AEZ compared to other EAZs at similar elevations.

No single pair of the three factors (AEZs, colony strength, and mean elevation) appeared to influence the defensive behaviour of the honeybees although individually they did. However, a combination of all the three factors had significant influence on the defensive behaviour of the honeybees. Interaction of several environmental factors has been found to influence the defensive behaviour of honeybees [45] which is an important trait in reducing attack and predation [46]. The defensive behaviour of African honeybees is associated with environmental conditions and the provocative factors within the locality [43]. This accounts for the variation of the defensive behaviour of the same honeybee race in different environmental conditions and locations.

\section{Conclusion}

Apis $m$. adansonii is more defensive compared with $A . m$. scutellata in Uganda. Mid North and Lake Albert Crescent agro-ecological zones have the most defensive honeybees, while the calmest honeybees were found in the West Nile agro-ecological zone. The type of bee hive used in beekeeping and the variation in vegetation cover do not affect the defensive behaviour of the honeybees.

Selection of honeybees that are less defensive for breeding programs could consider A. $m$ scutellata. Also, honeybee colonies from West Nile and Southern Highland AEZs may be considered when sourcing colonies with less defensive traits. Furthermore, to have honeybee colonies with less defensive behaviour, one may consider carrying out beekeeping at higher elevations. Beekeepers should not destroy defensive colonies as they normally do in preference for less defensive colonies since defensive colonies are associated with colony strength and thus high productivity. More research should be conducted on the effects of other factors such as temperature, apiary management, and pest and disease infestation on the defensive behaviour of the honeybees in Uganda.

\section{Conflicts of Interest}

The authors of this paper do hereby disclose that there are no conflicts of interest whatsoever in relation to this article. 


\section{Acknowledgments}

The authors acknowledge the government of Uganda through the National Agricultural Research Organization (NARO) for funding this research.

\section{References}

[1] G. H. Hall, C. Zettel-Nalen, and J. D. Ellis, "African Honey Bee: What You Need to Know," Florida, 2005, http://indian.ifas.ufl.edu/PDF/2006/AHB/ahb_pub.pdf.

[2] A. Tofilski, "Using geometric morphometrics and standard morphometry to discriminate three honeybee subspecies," Apidologie, vol. 39, no. 5, pp. 558-563, 2008.

[3] J. D. Ellis and A. Ellis, African Honey Bee, Africanized Honey Bee, Killer Bee, Apis mellifera scutellata Lepeletier (Insecta: Hymenoptera: Apidae), Gainesville, Fl, USA, 2009.

[4] M. D. Breed, E. Guzmán-Novoa, and G. J. Hunt, "Defensive behavior of honey bees: organization, genetics, and comparisons with other bees," Annual Review of Entomology, vol. 49, pp. 271-298, 2004.

[5] E. B. Atkinson and J. D. Ellis, "Adaptive behaviour of honeybees (Apis mellifera) toward beetle invaders exhibiting various levels of colony integration," Physiological Entomology, vol. 36, no. 3, pp. 282-289, 2011.

[6] A. Uzunov, C. Costa, B. Panasiuk et al., "Swarming, defensive and hygienic behaviour in honey bee colonies of different genetic origin in a pan-European experiment," Journal of Apicultural Research, vol. 53, no. 2, pp. 248-260, 2014.

[7] E. Guzmán-Novoa, D. Prieto-Merlos, J. L. Uribe-Rubio, and G. J. Hunt, "Relative reliability of four field assays to test defensive behaviour of honey bees (Apis mellifera)," Journal of Apicultural Research, vol. 42, no. 3, pp. 42-46, 2003.

[8] C. Andere, M. A. Palacio, E. M. Rodriguez, E. Figini, M. T. Dominguez, and E. Bedascarrasbure, "Evaluation of the defensive behavior of two honeybee ecotypes using a laboratory test," Genetics and Molecular Biology, vol. 25, no. 1, pp. 57-60, 2002.

[9] G. J. Hunt, E. Guzman-Novoa, J. L. Uribe-Rubio, and D. Prieto-Merlos, "Genotype-environment interactions in honeybee guarding behaviour," Animal Behaviour, vol. 66, no. 3, pp. 459-467, 2003.

[10] M. K. Zakour and K. Bienefeld, "Subjective evaluation of defensive behavior in the Syrian honeybee (Apis mellifera syriaca)," Journal of Apicultural Science, vol. 57, no. 2, pp. 137145, 2013.

[11] M. Arca, A. Papachristoforou, F. Mougel et al., "Defensive behaviour of Apis mellifera against Vespa velutina in France: Testing whether European honeybees can develop an effective collective defence against a new predator," Behavioural Processes, vol. 106, pp. 122-129, 2014.

[12] E. E. Southwick and R. F. A. Moritz, "Effects of meteorological factors on defensive behaviour of honey bees," International Journal of Biometerology, vol. 31, no. 3, pp. 259-265, 1987.

[13] A. M. Collins, "Effects of temperature and humidity on honeybee response to alarm pheromones," Journal of Apicultural Research, vol. 20, no. 1, pp. 13-18, 2015.

[14] T. Alemu, G. Legesse, and Z. Ararso, "Performance Evaluation of Honeybee (Apis mellifera scutellata) in Guji Zone," International Journal of Innovation and Applied Studies, vol. 9, no. 4, p. 93, 1987.
[15] M. Yang, S. Radloff, K. Tan, and R. Hepburn, "Anti-predator fan-blowing in guard bees, apis mellifera capensis esch," Journal of Insect Behavior, vol. 23, no. 1, pp. 12-18, 2009.

[16] M. Trhlin and J. Rajchard, "Chemical communication in the honeybee (Apis mellifera L.): A review," Veterinarni Medicina, vol. 56, no. 6, pp. 265-273, 2011.

[17] J. Corner, "Apiculture and bee management problems in African countries," in Proceedings of the 3 int- Conf Apia trap Climate, pp. 41-44, Nairobi, Kenya, 1985.

[18] G. J. Hunt, "Flight and fight: A comparative view of the neurophysiology and genetics of honey bee defensive behavior," Journal of Insect Physiology, vol. 53, no. 5, pp. 399-410, 2007.

[19] E. Guzmán-Novoa, G. J. Hunt, J. L. Uribe-Rubio, and D. Prieto-Merlos, "Genotypic effects of honey bee (Apis mellifera) defensive behavior at the individual and colony levels: The relationship of guarding, pursuing and stinging," Apidologie, vol. 35, no. 1, pp. 15-24, 2004.

[20] FAO, "Agro-Ecological Zoning Guidelines," FAO Soils Bull, vol. 76:35, 1996.

[21] G. Borsuk and J. Paleolog, "A rare case of over dominance in defensive behaviour of workers in honeybee colonies," Journal of Apicultural Science, vol. 49, no. 1, pp. 71-77, 2005.

[22] J.-C. Lenoir, D. Laloi, F.-X. Dechaume-Moncharmont, M. Solignac, and M.-H. Pham, "Intra-colonial variation of the sting extension response in the honey bee Apis mellifera," Insectes Sociaux, vol. 53, no. 1, pp. 80-85, 2006.

[23] R. F. Moritz, E. E. Southwick, and J. B. Harbo, "GENETIC analysis of defensive behaviour of honeybee colonies (apis mellifera 1.) in a field test," Apidologie, vol. 18, no. 1, pp. 27-42, 1987.

[24] P. A. Rydberg, "Phytogeographical notes on the rocky mountain region iv. forests of the subalpine and montane zones," Bulletin of the Torrey Botanical Club, vol. 42, no. 1, pp. 11-25, 1915.

[25] P. Kasangaki, G. Nyamasyo, P. Ndegwa et al., "Mitochondrial DNA (mtDNA) markers reveal low genetic variation and the presence of two honey bee races in Uganda's agro-ecological zones," Journal of Apicultural Research, vol. 56, no. 2, pp. 112121, 2017.

[26] D. C. Mistroa, L. A. D. Rodriguesa, and W. C. J. Ferreira, "The Africanized honey bee dispersal: a mathematical zoom," Bull Math Biol, vol. 67, Article ID 281312, pp. 281-323, 2005.

[27] M. H. Hussein, "Beekeeping in Africa," Apiacta, vol. 1, no. 2, pp. 32-48, 2001.

[28] M. Gbate, "Observations on the aggressive tendencies of Apis mellifera adansonii," Journal of Multidisciplinary Research, vol. 6, no. 2, pp. 32-36, 2014.

[29] J. S. King'ang'i Mbaya, Resource hoarding and defensive behaviours of African honey bees (Apis mellifera L.) in Kenya, University of Guelph, Kenya, 1993.

[30] J. L. Uribe-Rubio, T. Petukhova, and E. Guzman-Novoa, "Genotype and task influence stinging response thresholds of honeybee (Apis mellifera L.) workers of African and European descent," Open Journal of Ecology, vol. 03, no. 04, pp. 279-283, 2013.

[31] J. Woyke, "Some behavioural characteristics of the sudanese honey bee," Bee World, vol. 74, no. 3, pp. 133-140, 1993.

[32] P. Segeren, Beekeeping in the Tropics, Agromisa Foundation, Wageningen, Netherlands, 5th edition, 2004.

[33] A. M. Collins, T. E. Rinderer, and K. W. Tucker, "Colony Defense of Two Honeybee Types and their hydrid," Journal of Apicultural Research, vol. 27, no. 3, pp. 137-140, 1988. 
[34] S. S. Schneider and L. C. McNally, "Waggle dance behavior associated with seasonal absconding in colonies of the African honey bee, Apis mellifera scutellata," Insectes Sociaux, vol. 41, no. 2, pp. 115-127, 1994.

[35] F. Cánovas, P. De La Rúa, J. Serrano, and J. Galián, “Geographical patterns of mitochondrial DNA variation in Apis mellifera iberiensis (Hymenoptera: Apidae)," Journal of Zoological Systematics and Evolutionary Research, vol. 46, no. 1, pp. 24-30, 2008.

[36] A. Rahimi and M. Asadi, "Morphological characteristics of Apis mellifera meda (Hymenoptera: Apidae) in Saghez West of Iran," Nat Montenegrina, vol. 10, no. 2, pp. 101-107, 2010.

[37] B. P. Oldroyd and G. J. Thompson, "Behavioural Genetics of the Honey Bee Apis mellifera," Advances in Insect Physiology, vol. 33, pp. 1-49, 2006.

[38] M. K. Wray, H. R. Mattila, and T. D. Seeley, "Collective personalities in honeybee colonies are linked to colony fitness," Animal Behaviour, vol. 81, no. 3, pp. 559-568, 2011.

[39] J. Paleolog, "Behavioural characteristics of honey bee (Apis mellifera) colonies containing mix of workers of divergent behavioural traits," Animal Science Papers and Reports, vol. 27, no. 3, pp. 237-248, 2009.

[40] G. A. Adedeji, A. A. Aiyeloja, S. L. Larinde, and G. E. Omokhua, "Effect of seasons on colonisation and suitability of triplochiton scleroxylon K. Schum. Wood for Beekeeping in Rivers State, Nigeria," Natural Science, vol. 12, no. 8, pp. 117-122, 2014.

[41] J. Nakamura, M. W. Gikungu, Y. Kano, K. Hanzawa, M. Gichora, and Y. Morimoto, "Development of Beekeeping in Developing Countries and Practical Procedures - Case Study in Africa, Tokyo, 2009".

[42] J. Villa, "Defensive Behavior of Africanized and European honeybees at two elevations in Colombia," Journal of Apicultural Research, vol. 27, no. 3, pp. 141-145, 1988.

[43] B. A. Amssalu, Multivariate Morphometric Analysis And Behaviour of Honeybees (Apis mellifera L.) in The Southern Regions of Ethiopia, Rhodes University, South Africa, 2002.

[44] E. A. Omer, Studies on the Taxonomy of Honeybees in the Sudan, University of Khartoum, Sudan, 2007.

[45] C. Alaux, S. Sinha, L. Hasadsri et al., "Honey bee aggression supports a link between gene regulation and behavioral evolution," Evolution, vol. 1, no. 6, 2009.

[46] E. Guzman-Novoa, G. J. Hunt, R. E. Page Jr. et al., "Paternal effects on the defensive behavior of honeybees," Journal of Heredity, vol. 96, no. 3, pp. 1-5, 2005. 


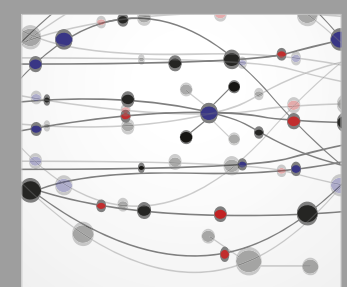

The Scientific World Journal
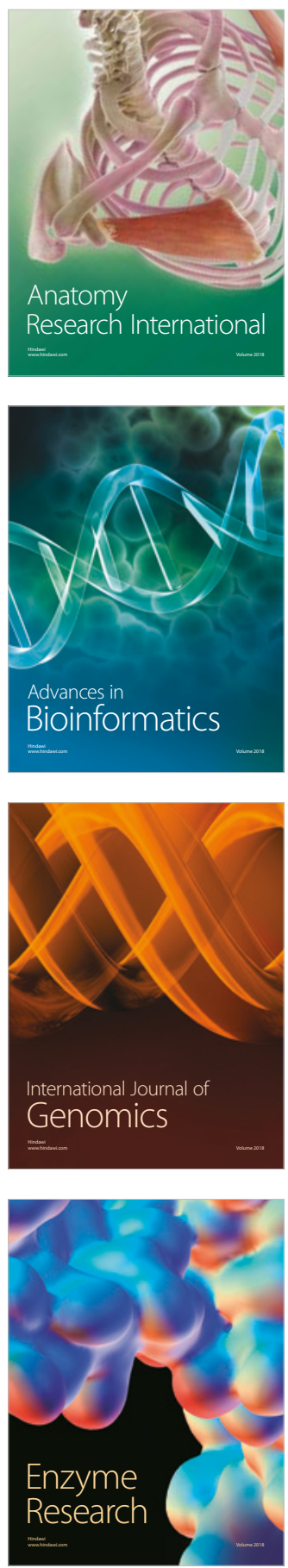
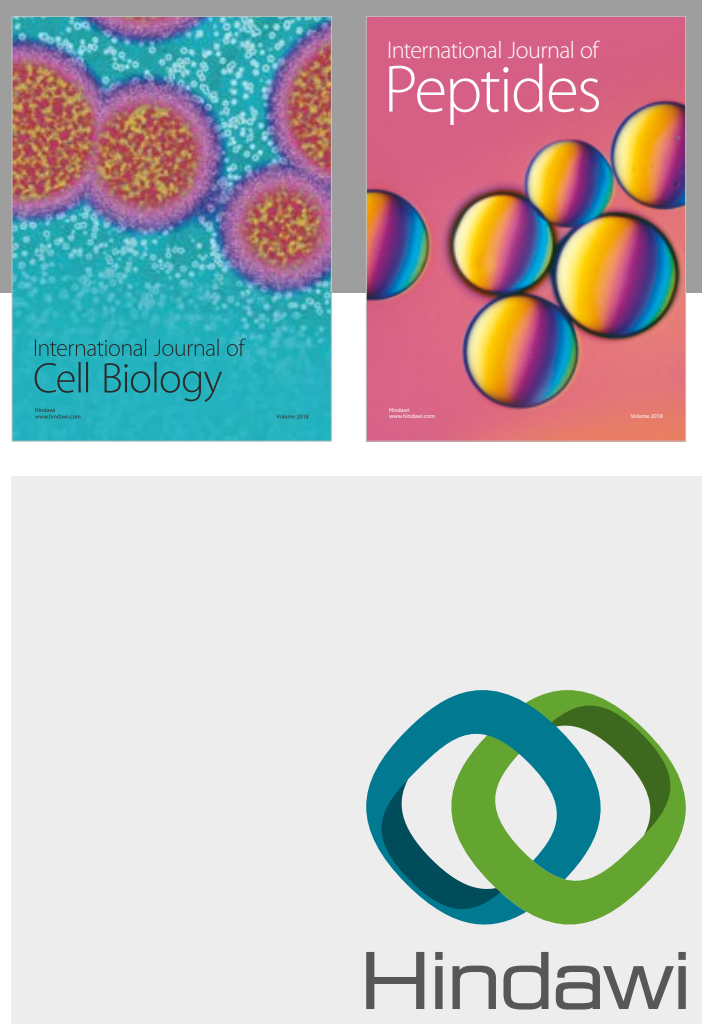

Submit your manuscripts at

www.hindawi.com
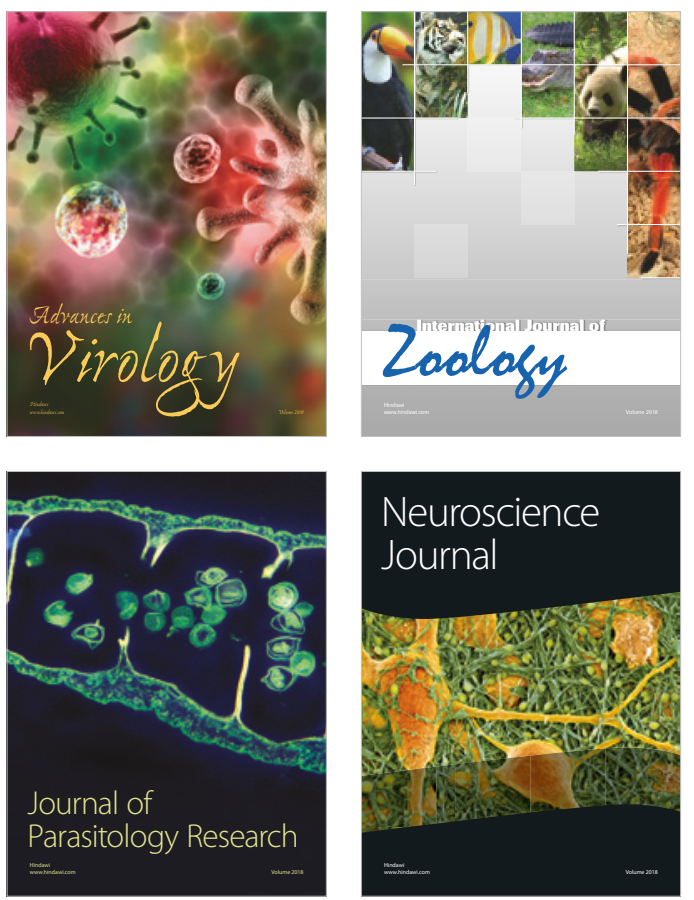
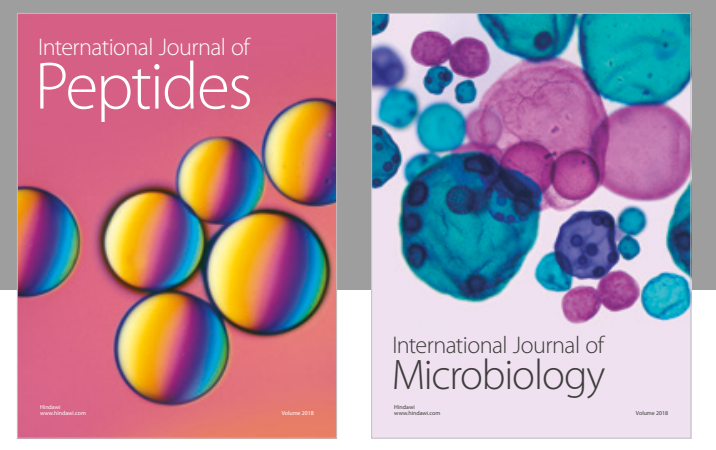

nternational Journal of Microbiology
Journal of
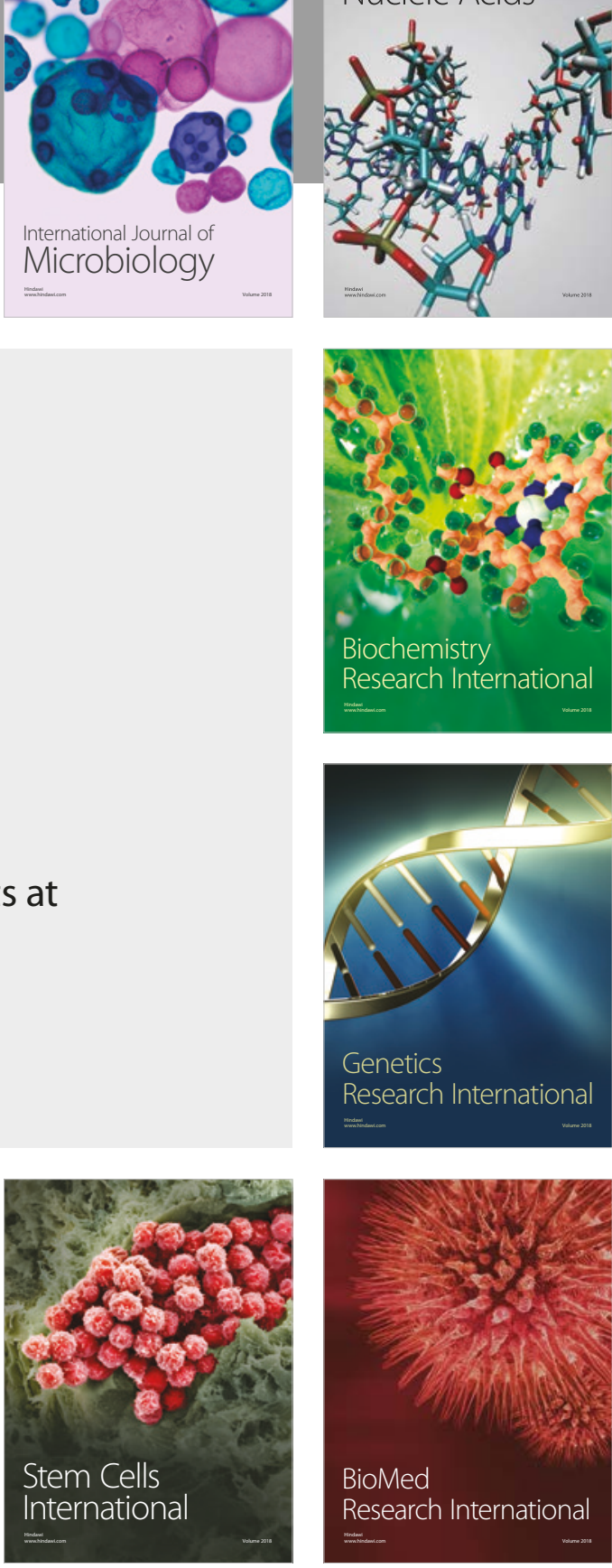
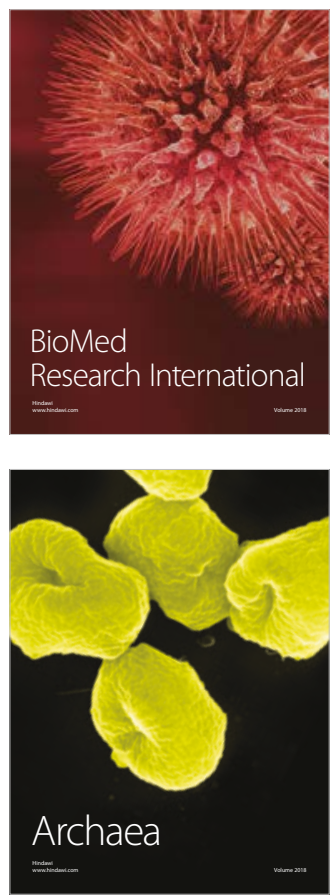